\title{
ANALISIS PENGGUNAAN TRACER DI PUSKESMAS ARIODILLAH PALEMBANG
}

\section{Siska Wulandari, Febrianti, Leni Herfiyanti}

Politeknik Piksi Ganesha Bandung Jawa Barat, Indonesia

Email: siskawulan1993@gmail.com, antyfebri15@gmail.com, leniherfiyanti@gmail.com

\begin{abstract}
Abstrak
Tracer merupakan Salah satu sarana di dalam ruangan filing rekam medis yang dapat dipakai sebagai tanda pengganti berkas rekam medis di rak filing yang berfungsi untuk mendeteksi keberadaan rekam medis. Berdasarkan hasil pengamatan di puskesmas Ariodillah Palembang penggunaan tracer belum efektif sehingga masih ditemukan terjadinya misfile yang menyebabkan rekam medis sulit terlacak. Tujuan dari penelitian ini untuk menganalisis penggunaan tracer di Puskesmas Ariodillah Palembang. Metode penelitian ini adalah deskriftif dengan pendekatan studi kasus. Penelitian deskriftif dengan pendekatan studi kasus berfungsi menggambarkan keadaan sistem penyimpanan dalam penggunaan tracer yang terjadi di Puskesmas Ariodillah Palembang. Teknik pengumpulan data dengan cara observasi dan wawancara. Subjek penelitian pada penelitian ini yaitu petugas penyimpanan. Objek yang diteliti yaitu rekam medis dan fasilitas sistem penyimpanan dalam penggunaan Tracer. Hasil penelitian di puskesmas Ariodillah palembang yaitu sudah memiliki Standar Operasional Prosedur tentang tracer khusus di ruang penyimpanan rekam medis. Standar Operasional Prosedur tersebut sudah ada, namun tanggal, nama pasien, tempat tujuan dicatat di buku ekspedisi bukan pada tracer yang diselipkan pada saat rekam medis keluar, bentuk tracer di Puskesmas Ariodillah Palembang hanya berupa tulisan berbentuk panah yang terbuat dari mika dengan dibedakan menjadi 3 warna yaitu biru, kuning dan merah.
\end{abstract}

Kata Kunci: tracer; penyimpanan; rekam medis

\section{Abstract}

Tracer is one of the facilities in the medical record filing room that can be used as a substitute for medical record files on the filing shelf which functions to detect the presence of medical records. Based on observations at the Ariodillah Health Center in Palembang, the use of Tracer has not been effective, so there are still misfiles that make medical records difficult to trace. The purpose of this study was to analyze the use of Tracer in Ariodillah Health Center Palembang. This research method is descriptive with a case study approach. Descriptive research serves to describe the state of the storage system in the use of Tracer that occurred at the Ariodillah Health Center Palembang. Data collection techniques by means of observation and interviews. The research subjects in this study were medical records, storage officers. The object under study is the storage system facility in the use of Tracer. The results of the research at the Ariodillah Health Center in Palembang, namely that they already have Standard Operating Procedures on

$\begin{array}{ll}\text { How to cite: } & \text { Wulandari, S., Febrianti, F., \& Herfiyanti, L. (2021). Analisis Penggunaan Tracer Di Puskesmas } \\ & \text { Ariodillah Palembang, Syntax Idea, 3(8), https://doi.org/10.36418/syntax-idea.v3i8.1452 } \\ \text { E-ISSN: } & \text { 2684-883X } \\ \text { Published by: } & \text { Ridwan Institute }\end{array}$


special Tracers in the medical record storage room. The Standard Operating Procedure already exists, but the date, patient name, place of destination are recorded in the expedition book not on the Tracer which is inserted when the medical record comes out, the Tracer form at the Ariodillah Health Center Palembang is only in the form of arrow-shaped writing made of mica divided into 3 colors are blue, yellow and red.

Keywords: tracer; filing; medical records

\section{Pendahuluan}

Pelayanan kesehatan tingkat pertama di Indonesia dalam pengobatan dasar adalah puskesmas, puskesmas merupakan suatu institusi kesehatan fungsional dalam peningkatan kesehatan yang berperan pada masyarakat di daerah kerjanya dan memberikan pelayanan secara merata serta terpadu. Tugas puskesmas adalah sebagai titik pembangunan dalam upaya memberikan pelayanan dan pengobatan masyarakat di wilayah kerjanya (Peraturan Menteri Kesehatan RI No 43 tahun 2019). Dalam memberikan pelayanan kesehatan ada faktor yang membantu untuk melancarkan dalam proses pelayanan pasien yaitu rekam medis.

Rekam medis merupakan salah satu tenaga pelayanan kesehatan non medik di suatu pelayanan kesehatan baik dirumah sakit ataupun dipelayanan kesehatan lainnya, yang selalu menjadi peran utama dalam peningkatan mutu pelayanan medis. Rekam medis adalah catatan atau dokumen informasi data pasien berupa identitas pasien, pengobatan, pemeriksaan dan tindakan yang sudah dilakukan oleh tenaga kesehatan di suatu pelayanan kesehatan yang telah diberikan kepada pasien (Depkes, 2006). Keakuratan informasi yang baik dan lengkap dapat juga berguna saat menolong pasien dalam keadaan apapun, sehingga informasi yang lengkap dapat juga membantu pasien dalam melakukan instruksi klinis dan dapat mempebaharui hasil pelayanan kesehatan pasien (Hatta, 2008).

Rekam medis yang baik ialah selalu memberikan pelayanan yang baik kepada pasien serta fasilitas pelayanan kesehatan lainnya. Pengelolahan data pasien dimulai dari pengregistrasian pasien hingga pengarsipan rekam medis di ruangan filing. Rekam medis juga berperan penting dalam pengelolahan data dan informasi pasien, supaya kualitas informasi data kesehatan tetap terjaga (Maryati, 2017). Berkesinambungan data dan menjaga nilai rekam medis yang baik merupakan sesuatu yang mutlak dan baik agar nilai rekam medis dapat mendukung pelayanan kesehatan menjadi maksimal (Kinanty, 2016).

Penyediaan berkas rekam medis yang cepat dan tepat sangat membantu dalam kualitas pelayanan kesehatan kepada pasien. Oleh karena itu, permasalahan di dalam filing merupakan hal penting agar diperhatikan. Jika dalam sistem filing yang digunakan kurang baik, akan muncul masalah yang dapat mengganggu dalam penyediaan berkas rekam medis secara tepat dan cepat (Anhar et al., 2018). Penyediaan rekam medis yang cepat dan tepat waktu dapat mempengaruhi dalam pelayanan pengobatan pasien, oleh 
karena itu agar meminimalisir kesalahan dalam penyediaan rekam medis yang cepat, salah satunya ialah dengan menggunakan tracer (Purwanto, 2020).

Tracer merupakan Salah satu sarana di dalam ruangan filing rekam medis yang dapat dipakai sebagai tanda pengganti berkas rekam medis di rak filing yang berfungsi untuk mendeteksi keberadaan rekam medis (Budi, 2015). Pentingnya tracer sebagai pendeteksi berkas rekam medis saat keluar dari rak penyimpanan berkas rekam medis sangat perlu untuk di informasikan kepada tenaga kesehatan rekam medis dalam hal ini puskesmas. informasi ini diharapkan dapat membuat dalam upaya pemanfaatan Tracer sebagai kartu pelacak atau mendeteksi keberadaan berkas rekam medis ketika keluar dari rak penyimpanan (Musfika, 2020). Dengan adanya fasilitas tracer diruangan filing, supaya rekam medis menjadi lebih mudah dalam menemukan kembali berkas rekam medis pada saat dibutuhkan (Valentina, 2019).

Tujuan dari penelitian ini untuk menganalisis penggunaan tracer di Puskesmas Ariodillah Palembang, sedangkan manfaat penelitian ini yaitu sebagai bahan masukan dan pertimbangan mengenai penggunaan tracer sehingga dapat memaksimalkan kinerja petugas rekam medis dalam melakukan pelacakan rekam medis di Puskesmas Ariodillah Palembang.

\section{Metode Penelitian}

Metode penelitian yang digunakan dalam penelitian ini adalah deskriptif dengan pendekatan studi kasus. Penelitian deskriptif dengan pendekatan studi kasus berfungsi menggambarkan keadaan sistem penyimpanan dalam penggunaan Tracer yang terjadi di Puskesmas Ariodillah Palembang. Teknik pengumpulan data dengan cara observasi dan wawancara. Subjek penelitian pada penelitian ini yaitu petugas penyimpanan. Objek yang diteliti yaitu rekam medis dan fasilitas sistem penyimpanan dalam penggunaan tracer. Penelitian ini dilakukan pada bulan Juni 2021 di Puskesmas Ariodillah Palembang.

\section{Hasil dan Pembahasan}

\section{Standar Operasional Prosedur Penggunaan Tracer}

Di bawah ini Standar Operasional Prosedur dengan nomor 440/034/UKP/SOP/VII/2019 penggunaan tracer di Puskesmas Ariodillah Palembang yang berlaku sejak 2019:

a. Petugas meregister pasien di buku register

b. Petugas membawa KIB ke bagian penyimpanan

c. Petugas menyiapkan trecer dan bon peminjaman

d. Petugas mencatatat di bon peminjaman dengan kelengkapan sebagai berikut:

1) Mengisi tanggal peminjaman

2) Mengisi nomor rekam medis

3) Mengisi nama pasien

4) Mengisi tujuan peminjaman

e. Petugas menyisipkan bon peminjaman di tracer 
f. Petugas memasukan tracer ke bagian rekam medis yang dikeluarkan

g. Petugas mengisi buku ekspedisi

h. Setelah rekam medis di kembalikan ke ruang penyimpanan petugas mencocokan nomor rekam medis dengan tracer

i. Petugas memasukan rekam medis dan mencabut tracer.

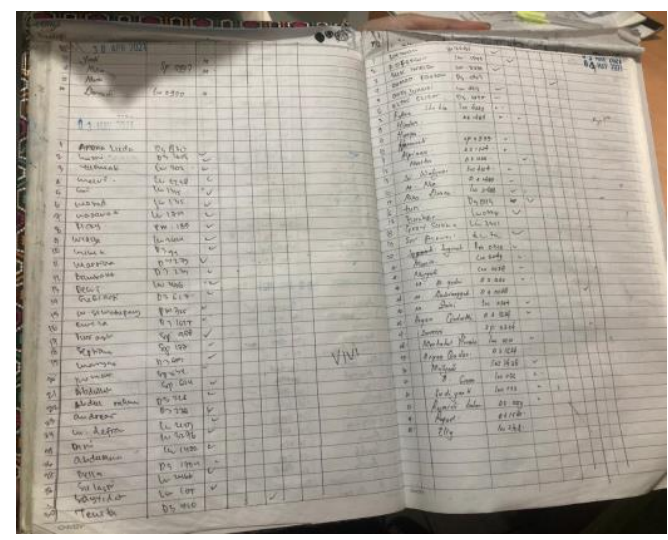

Gambar 1

\section{Buku Ekspedisi Puskesmas Ariodillah Palembang}

Berdasarkan hasil penelitian pada bulan Juni tahun 2021 di Puskesmas Ariodillah Palembang sudah memiliki Standar Operasional Prosedur tentangt tracer khusus di ruang penyimpanan rekam medis. Standar Operasional Prosedur tersebut sudah ada. namun semua (tanggal, nama pasien, tempat tujuan) dicatat di buku ekspedisi seperti pada Gambar 1 bukan pada tracer yang diselipkan pada saat rekam medis keluar.

Standar Prosedur Operasional (SOP) adalah sistem yang disusun untuk memudahkan, dan merapikan pekerjaan. Sistem ini berisi urutan proses melakukan pekerjaan dari awal sampai akhir (Suhartina, 2019). Hal ini sejalan dengan penelitian yang dilakukan oleh (Masyfufah \& Yayasan Rumah Sakit Soetomo, 2017) yang menyatakan bahwa prosedur atau tahap-tahap dalam Standar Operasional Prosedur harus dibaca dan dilaksanakan sehingga dapat diimplementasikan dengan maksimal.

\section{Tabel 1}

Karakteristik Responden

\begin{tabular}{cccc}
\hline Informan & Umur & Jenis Kelamin & Pendidikan \\
\hline Informan 1 & 24 & Perempuan & SMA \\
\hline Informan 2 & 25 & Perempuan & SMA \\
\hline Infprman 3 & 26 & Perempuan & DIII Kebidanan \\
\hline Informan 4 & 27 & Perempuan & DIII Rekam Medis \\
\hline Informan 5 & 29 & Perempuan & DIII Kebidanan \\
\hline
\end{tabular}

Berdasarkan hasil penelitian di Puskesmas Ariodillah Palembang karakteristik petugas berdasarkan pendidikan sebagian besar petugas penyimpanan rekam medis 
memiliki pendidikan non rekam medis yaitu berjumlah 4 orang sedangkan yang memiliki pendidikan rekam medis hanya 1 orang. Pendidikan memberikan pengetahuan yang di butuhkan untuk menyelesaikan pekerjaan. Semakin tinggi pendidikan, semakin banyak pengetahuan yang di miliki untuk melakukan pekerjaan itu, semakin tinggi tingkat pendidikan maka produktivitas tenaga kerja semakin tinggi, tapi semakin rendah tingkat pendidikan maka produktivitas tenaga kerja semakin rendah (Ukkas, 2017).

Berdasarkan Karakteristik pendidikan bahwa pengetahuan petugas dalam sistem penyimpanan rekam medis belum sesuai dengan Standar Operasional Prosedur penyimpanan di puskesmas Ariodillah Palembang sehingga mempengarui pekerjaan petugas. Pengetahuan petugas menentukan berhasil atau tidaknya tugas yang diberikan padanya, petugas pengetahuannya cukup akan meningkatkan efisien perusahaan. Hal ini sejalan dengan penelitian yang dilakukan oleh (Masyfufah \& Yayasan Rumah Sakit Soetomo, 2017) yang menyatakan bahwa pengetahuan responden di kategorikan baik itu perlu penguasaan pengetahuan, perilaku dan keterampilan yang profesional.

\section{Sistem Penyimpanan}

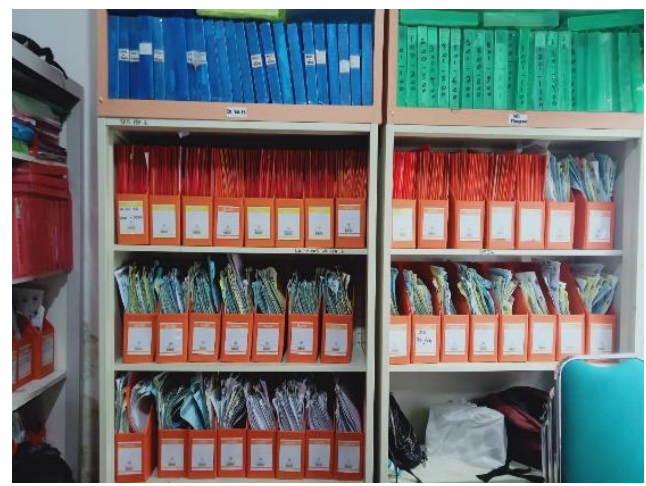

Gambar 2

\section{Ruang Penyimpanan Puskesmas Ariodillah Palembang}

Berdasarkan Hasil penelitian di Puskesmas Ariodillah Palembang menggunakan rak penyimpanan terbuka dengan memakai box file untuk penyimpanan rekam medis dengan sistem penyimpanan menggunakan desentralisasi yaitu rekam medis rawat jalan dan rawat inap dipisahkan karena di Puskesmas Ariodillah Palembang belum ada pelayanan rawat inap. Sistem penomoran di Puskesmas Ariodillah menggunakan family folder yaitu satu nomor rekam medis digunakan untuk satu keluarga serta sistem penjajaran di puskesmas Ariodillah menggunakan (Straight Numerical flling) yaitu menjajarkan rekam medis berdasarkan urutan langsung nomor rekam medis. Adapun sarana dan prasarana yang ada di Puskesmas Ariodillah Palembang seperti pada tabel 2 di bawah ini: 
Tabel 2

Sarana Prasarana di Puskesmas Ariodillah Palembang

\begin{tabular}{|c|c|c|}
\hline No & Nama Barang & Jumlah \\
\hline 1 & Buku Register & 1 \\
\hline 2 & Staples & 2 \\
\hline 3 & Boxfile & 100 \\
\hline 4 & ATK & 2 \\
\hline 5 & Tracer & 120 \\
\hline 6 & Buku Ekspedisi & 1 \\
\hline 7 & Alat Pelubang Kertas & 2 \\
\hline 8 & Meja dan Kursi & 1 \\
\hline 19 & Rak Terbuka & 5 \\
\hline 10 & Telepon & 1 \\
\hline 11 & Komputer & 1 \\
\hline 12 & Lemari & 1 \\
\hline 13 & Printer & 1 \\
\hline 14 & Map (Folder) & 200 \\
\hline 15 & KIB & 150 \\
\hline 16 & KIUP & 100 \\
\hline
\end{tabular}

Sarana yang di butuhkan di ruang penyimpanan rekam medis yaitu Rak terbuka, Lemari lima laci, Rak statis dan dinamis, Lemari arsip, Penyekat, Map, Penunjuk, Kata tangkap, Alat Kearsipan, dan Tangga.

\section{Penggunaan Tracer}

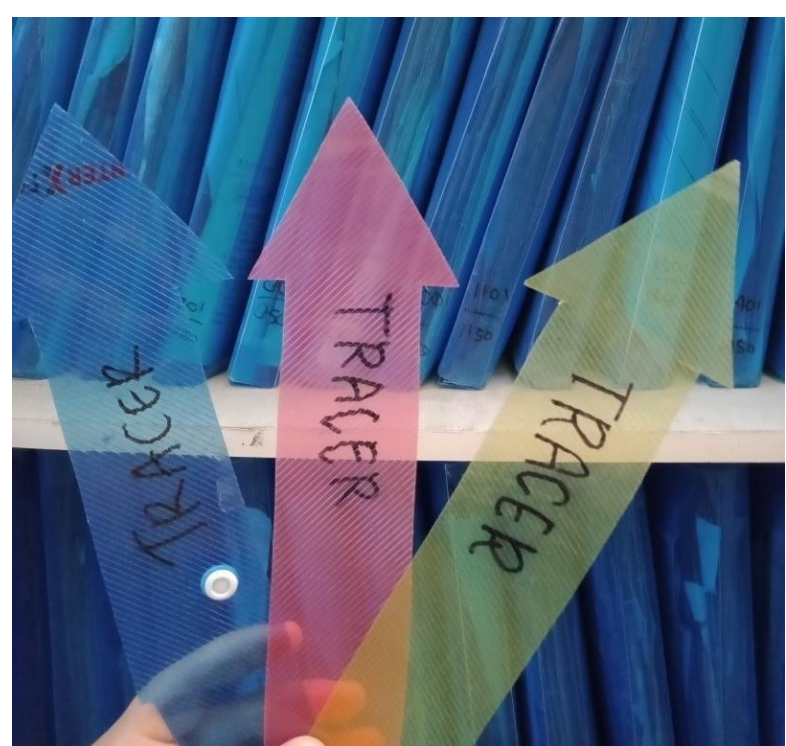

Gambar 3 Tracer Puskesmas Ariodillah Palembang

Tracer merupakan alat penting untuk memantau penggunaan rekam medis dan di tempatkan sebagai pengganti rekam medis yang diambil dari rak penyimpanan. Kartu 
yang dipinjam atau petunjuk keluar akan tetap berada dalam rak sampai rekam medis yang di ambil (di pinjam) dikembalikan ke tempat asalnya. Tracer biasanya digunakan dalam bentuk kartu yang keras dan tahan lama (kertas) dengan kantong perekat untuk menyimpan surat pinjaman (Wardani, Dyah Ayu., Lestari, Tri., 2012).

Berdasarkan hasil penelitian di Puskesmas Ariodillah Palembang sudah menggunakan tracer dalam pengambilan saat rekam medis keluar dari rak penyimpanan. Di Puskesmas Ariodillah Palembang tracer dibedakan menjadi 3 warna seperti pada gambar 3 yaitu warna kuning, biru dan merah. tracer warna biru digunakan pada hari Senin dan Kamis, tracer kuning digunakan pada hari selasa dan jumat sedangkan tracer merah digunakan pada hari Rabu dan Sabtu. Hal tersebut dibuat agar petugas mengetahui apabila ada rekam medis yang belum kembali sesuai dengan warna hari pengambilan.

Bentuk tracer di Puskesmas Ariodillah Palembang hanya berupa tulisan berbentuk panah yang terbuat dari mika yang dibedakan warna sesuai hari. Sedangkan di Standar Operasional Prosedur yang dibuat puskesmas Ariodillah Palembang tracer itu harus memuat nama, tanggal dan tujuan penggunaan namun catatan yang berupa nama, tanggal dan tujuan penggunaan hanya di tulis di buku ekspedisi.

Dari temuan penelitian di lapangan belum sejalan dengan (Nurarif \& Kusuma, 2013) yang menyatakan tracer dibuat dari karton atau plastik tebal yang awet agar tidak mudah kusut atau robek yang di lengkapi plastik tebal dengan kantung untuk meletakkan slip peminjaman rekam medis dan lembar kertas yang bisa di lepas untuk mencatat Nomor rekam medis, Nama Pasien, tanggal pinjam dan keperluan peminjaman.

Berdasarkan hasil wawancara terhadap salah satu informan penggunaan Tracer di Puskesmas Ariodillah Palembang belum berjalan efektif sehingga masih ditemukan terjadinya missfile yang menyebabkan rekam medis sulit terlacak. Dikarenakan jumlah tracer tersedia hanya 120 tracer (40 warna biru, 40 warna kuning, 40 warna merah) sedangkan pasien yang datang ke Puskesmas Ariodillah Palembang perhari bisa sampai 70 atau 80 pasien sehingga dirasa kurang.

Menurut (Budi, 2015) terjadinya misfile atau kesalahan penyimpanan membuat pelayanan menjadi kurang efisien dan efektif sehingga petugas kesulitan mencari rekam medis dan tracer merupakan faktor pendukung untuk memudahkan petugas dalam pencarian rekam medis.

\section{Kesimpulan}

Dari hasil penelitian yang dilakukan pada bulan Juni 2021 di Puskesmas Ariodillah Palembang diambil kesimpulan bahwa di Puskesmas Ariodillah Palembang sudah ada Standar Operasional Prosedur khusus penggunaan tracer di ruang rekam medis dan sudah dijalankan namun tanggal, nama pasien, tempat tujuan dicatat di buku ekspedisi bukan pada tracer yang diselipkan pada saat rekam medis keluar. Tracer tersebut dibedakan menjadi 3 warna yaitu warna biru, kuning, merah dan kurangnya 
jumlah tracer menyebabkan terjadinya misfile. Sehingga penggunaan Tracer di Puskesmas Ariodillah Palembang perlu dilakukan evaluasi kembali

\section{BIBLIOGRAFI}

Nurarif \& Kusuma, (2013). Daftar Isi Buku Pedoman Rekam Medis Daftar. Journal of Chemical Information and Modeling, 53(9), 1689-1699.Google Scholar

Anhar, A. Al, Ningsih, E. R., \& Rosada, A. (2018). Perancangan Dan Prosedur Penggunaan Tracer ( Petunjuk Keluar ) Pada Penyimpanan Dokumen Rekam Medis Di Rumah Sakit Bhayangkara Tk III Hoegeng Iman Santoso Banjarmasin. Penguatan Pendidikan Tenaga Kesehatan Di Era Industri 4.0, 23-30. Google Scholar

Budi, S. C. (2015). Pentingnya Tracer Sebagai Kartu Pelacak Berkas Rekam Medis Keluar dari Rak Penyimpanan. Jurnal Pengabdian Kepada Masyarakat (Indonesian Journal of Community Engagement), 1(1), 121. Google Scholar

Depkes. (2006). Pedoman Manajemen Sumber Daya Manusia (Sdm) Kesehatan Dalam Penanggulangan Bencana. Jurnal Kesehatan, 13. Google Scholar

Hatta, G. R. (2008). Pedoman Manajemen Informasi Kesehatan di sarana pelayanan kesehatan. Jakarta: Universitas Indonesia. Google Scholar

Kinanty, A. A. (2016). Faktor-Faktor Yang Memengaruhi Faktor-Faktor Yang Memengaruhi. 19(1), 38-46.

Maryati, Y. (2017). Manajemen Mutu Informasi Kesehatan II. Akreditasi Dan Manajemen Risiko.

Masyfufah, L. A., \& YayasanRumahSakit Soetomo, S. (2017). Factors Affecting Implementation of Standard Operating Procedures Tracer of Medical Record of Islamic Hospital Surabaya. Jurnal Manajemen Informasi Kesehatan Indonesia, 5(2), 2337-2585. Google Scholar

Musfika, M. (2020). Tinjauan Faktor-Faktor Penghambat Pelaksanaan Tracer Di Rumah Sakit Griya Husada Madiun. Jurnal Delima Harapan, 7(1), 58-64. Google Scholar

Peraturan Menteri Kesehatan RI No 43 tahun 2019. (2019). Peraturan Menteri Kesehatan RI No 43 tahun 2019 tentang Puskesmas. Peraturan Menteri Kesehatan RI No 43 Tahun 2019 Tentang Puskesmas, Nomor 65(879), 2004-2006.

Purwanto, M. (2020). Literature Review Gambaran Penggunaan Tracer Terhadap Literature Review.

Suhartina, I. (2019). Analisis Efektivitas SOP Pelaksanaan Penyimpanan Berkas Rekam 
Siska Wulandari, Febrianti, Leni Herfiyanti

Medis Di Puskesmas Lawang. Jurnal Manajemen Informasi Kesehatan Indonesia, 7(2), 128. Google Scholar

Ukkas, I. (2017). Faktor-Faktor Yang Mempengaruhi Produktivitas Tenaga Kerja Industri Kecil Kota Palopo. Kelola: Journal of Islamic Education Management, 2(2). Google Scholar

Valentina. (2019). Tinjauan Sistem Penyimpanan Rekam Medis Menurut Standar Akreditasi Puskesmas Di Puskesmas Sukaramai Tahun 2019. Jurnal Ilmiah Perekam Dan Informasi Kesehatan Imelda, 4(1), 554-559. Google Scholar

Wardani, Dyah Ayu., Lestari, Tri., dan H. (2012). Tinjaun Pelaksaan Prosedur Peminjaman Dokumen Rekam Medis Di Unit Filing Rumah Sakit Umum Daerah Pandan Arang Boyolali Tahun 2012. Stikes, VI, 59-71. Google Scholar

\section{Copyright holder:}

Siska Wulandari, Febrianti, Leni Herfiyanti (2021)

First publication right:

Syntax Idea

This article is licensed under:

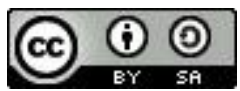

